

\section{Sumário}

\section{Dossier Federalismo}

Forma de Estado: Federalismo e RePartição de CompetênCIAS ...................................... 2

Carlos Bastide Horbach

IMUNIDADE RECÍPROCA E FEDERALISMO: DA CONSTRUÇÃO NORTE-AMERICANA À ATUAL POSIÇÃO Do STF

Fernando Santos Arenhart

JUSTIÇA FISCAL, PAZ TRIBUTÁRIA E OBRIGAÇõES REPUBLICANAS: UMA BREVE ANÁLISE DA DINÂMICA JuRisprudencial tributária do Supremo Tribunal Federal ............................................34

Luís Carlos Martins Alves Jr

Federalismo, estado Federalista e a REVALORIZAÇÃo do mUNicípio: UM NOVO CAMINHO PARA O SÉCULO XXI?

Antonio Celso Batista Minhoto

EfEITOS POLÍtTICO-JURÍdicos DA NÃo INSTITUCIONALIZADA PARADIPLOMACIA NO BRASIL ..........66

Gustavo de Souza Abreu

The Management of Public Natural Resource Wealth.

Paul Rose

A (IN)COMPETÊNCIA DO CONAMA PARA EDIÇÃo DE NORMAS SOBRE LICENCIAMENTO AMBIENTAL: ANÁLISE DE SUA JURIDICIDADE ...................................................................................... 118

André Fagundes Lemos

\section{Artigos sobre outros temas}

TEORÍA DE LA PRESIÓN TRIBUTARIA EN BASE A LA IGUALDAD INTERGENERACIONAL: UNA PERSPECTIVA FINANCIERA Y TRIBUTARIA DEL CASO ARGENTINO.

Luciano Carlos Rezzoagli e Bruno Ariel Rezzoagli

CRÉdito TRIBUTÁRIO: GARANTIAS, PRIVILÉGIOS E PREFERÊNCIAS.

Luís Carlos Martins Alves Júnior

Tributário - O parecer PGFN/CRJ 492/2011 e os efeitos da coisa Julgada inconstitucional em face da segurança jurídica no Estado Democrático de Direito* 
A seguranÇa jurídica administrativa na jurisprudência do Supremo Tribunal Federal: UMA ANÁLISE ACERCA DOS FUNDAMENTOS NORMATIVOS E DOS ARGUMENTOS JURÍDICOS NOS JULGAMENTOS DOS MANDADOS DE SEGURANÇA 24.781 E 25.116 195

Ana Paula Sampaio Silva Pereira

Avaliação legislativa no Brasil: apontamentos para uma nova AgENDA de PESQUiSa SoBRE O MODO DE PRODUÇÃO DAS LEIS.....................................................................229

Natasha Schmitt Caccia Salinas

Políticas públicas, DeVERES Fundamentais E CONCRETIZaÇão de DiReitos Julio Pinheiro Faro

Políticas públicas de guerra Às drogas: o ESTAdo de EXCEÇão E A transiÇão do inimigo SCHMitTiano ao homo SaCER de Agamben João Victor Nascimento Martins

NEW INSTITUTIONS FOR THE PROTECTION OF PRIVACY AND PERSONAL DIGNITY IN INTERNET COMMUNICATION - "INFORMATION BROKER", "PRIVATE CYBER COURTS" AND NETWORK OF CONTRACTS

Karl-Heinz Ladeur

RESPONSABILIDADE CIVIL DECORRENTE DE ERRO MÉDICO.

Edilson Enedino das Chagas e Héctor Valverde Santana

A atual geração de energia elétrica SEgundo a lógica de merCado e SuA Ainda CaraCTERIZAÇÃO COMO SERVIÇO PÚBLICO.

Humberto Cunha dos Santos

EMPRESAS, RESPONSABILIDADE SOCIAL E POLÍTICAS DE INFORMAÇÃo OBRIGATÓRIA NO BRASIL.....

Leandro Martins Zanitelli

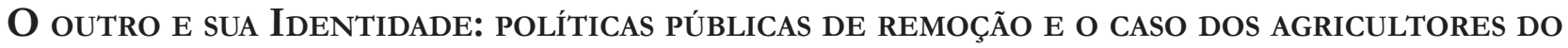
Parque Estadual da Pedra Branca/RJ.

Andreza A. Franco Câmara

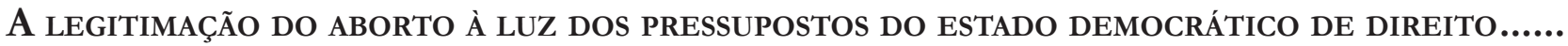

Terezinha Inês Teles Pires

JUSPOSITIVISMO, DISCRICIONARIEDADE E CONTROLE JUDICIAL DE POLÍTICAS PÚBLICAS NO DIREITO BRASILEIRO

Guilherme Valle Brum

A governança transnacional ambiental na Rio +20 . Paulo Márcio Cruz e Zenildo Bodnar 
O QUE É UMA BOA TESE DE DOUTORADO EM DiREITO? UMA ANÁlise A PARTIR DA PRÓPRIA PERCEPÇÃO DOS PROGRAMAS ............................................................................424

Nitish Monebhurrun e Marcelo D. Varella

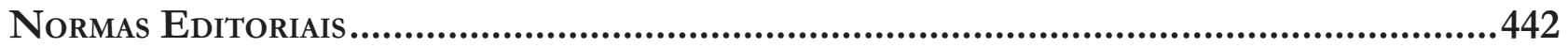

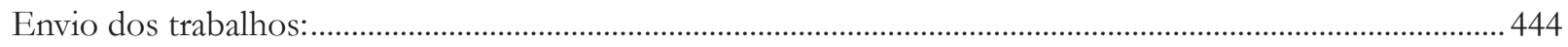




\title{
Efeitos político-jurídicos da não institucionalizada paradiplomacia no Brasil
}

\author{
Political-legal effects of the \\ noninstitutionalized paradiplomacy in Brazil*
}

Gustavo de Souza Abreu**

\section{Resumo}

O Estado brasileiro resiste à institucionalização da atividade paradiplomática e isso dificulta a aplicação de certas políticas públicas direcionadas ao desenvolvimento socioeconômico de estados e municípios, além de comprometer a credibilidade do país e aspectos da segurança nacional. Este artigo tem por objetivo analisar brevemente o fenômeno da paradiplomacia, apontando as consequências de sua continuidade nos padrões vigentes. Primeiramente, são apresentados aspectos conceituais e alguns modelos de paradiplomacias institucionalizadas no mundo. A seguir, o fenômeno é contextualizado no Brasil, onde se identifica um problema jurídico materializado por iniciativas de governos locais no plano internacional que, a rigor, seriam da competência da União. Constata-se que o Estado apresenta posturas opostas em relação à questão: é resistente à institucionalização, por temer a perda de soberania; mas é tolerante quanto ao seu exercício, diante da inexorabilidade do fenômeno. Dessa dúbia postura, resultam quatro consequências: (i) prejuízos ao desenvolvimento local e regional; (ii) insegurança jurídica; (iii) constrangimentos no plano internacional; e (iv) riscos à segurança nacional. Na parte fundamental da análise, destacando as duas últimas consequências, argumenta-se que o caráter não institucional da paradiplomacia conduz a um problema político-jurídico para o Estado. Finalmente, conclui-se pela imprescindibilidade da institucionalização da atividade, ressaltando-se as implicações negativas da continuidade do padrão vigente. Mesmo sem apresentar um modelo jurídico para a solução do problema, o artigo abre perspectivas para reflexões nessa direção, com a originalidade de juntar aos argumentos já conhecidos na literatura a questão dos constrangimentos internacionais e dos riscos à segurança nacional.

Palavras-chave: Paradiplomacia. Política externa. Políticas públicas. Soberania. Subsidiariedade. Segurança nacional.

* Recebido em 03/07/2013 Aprovado em 25/07/2013

** Assessor de política e estratégia do Ministério da Defesa e Mestre em Direito pelo Centro Universitário de Brasília (Uniceub). Email: elvabreu@uol.com.br

\section{Abstract}

The Brazilian State resists in institutionalizing the paradiplomacy. This attitude hampers the construction of certain public policies aimed towards social and economic development in states and municipalities and compromises the country's credibility and national security. The aim of this article is to make a brief analysis about paradiplomacy, focusing on the consequences of the continuity of this noninstitutionalized activity. Firstly, conceptual as- 
pects and some models of institutionalized paradiplomacies around the world are presented. Secondly, the phenomenon is contextualized in Brazil, where a legal problem is materialized by the growing development of procedures in the international field that do not observe some constitutional competencies that are exclusives of central power. With regard to this phenomenon the State adopts opposite postures: resists to institutionalization, fearing losing sovereignty, but is tolerant by perceiving its inevitability. Keeping the dubious attitude results in four important consequences: ( $)$ damage to regional development, (ii) legal uncertainty, (iii) constraints in the international field, and (iv) risks to national security. In the fundamental part of this analysis, highlighting the last four consequences, it is argued that the paradiplomacy with no institutionalization carries on to a political-legal problem to the State. Finally, it concludes that the institutionalization of paradiplomacy in Brazil is essential and points out to the negative implications if the legislation in force is maintained. The article does not intend to find a solution to the problem; however it opens up some ways of thinking about this matter, with the originality of joining well-known arguments to a new approach related to international constraints and national security risks.

Keywords: Paradiplomacy. Foreign policy. Public policies. Sovereignty. Subsidiarity. National security.

\section{INTRODUÇÃo}

Este artigo traz à reflexão a questão da não institucionalizada paradiplomacia no Brasil. A temática em si não constitui novidade na literatura acadêmica nacional que, de um modo geral, destaca as dificuldades enfrentadas por estados e municípios no campo do diálogo internacional e critica o desinteresse e a acomodação dos tomadores de decisão que pouco fazem no sentido de institucionalizar a atividade.

O que de novo se quer apresentar é uma perspectiva dos constrangimentos a que o Estado brasileiro se submete ao permanecer passivo, sob o duvidoso argumento de que, ao descentralizar poderes para o exercício de certos atos internacionais que lhes são tradicionalmente próprios, estaria perdendo soberania. Em verdade, como se buscará demonstrar, ao permanecer inflexível e ao mesmo tempo tolerante, o Estado brasileiro propicia, paradoxalmente, o fomento de procedimentos à margem da lei que podem justamente comprometer o seu poder soberano.

Para além do ordenamento jurídico interno, diante da percepção das fronteiras não mais como uma linha de separação de interesses nacionais, mas como loci de aproximação de Estados, há de se pretender que regras jurídicas mais ou menos comuns sejam observadas. Nesse sentido, tem-se uma leitura da temática da paradiplomacia inscrita na tendência de mundialização do Direito, tendo em vista a necessidade da existência de regras mínimas para a regulação de espaços internacionais comuns nos quais entes subnacionais possam atuar sem ferir o princípio da soberania dos Estados.

Há vários exemplos no mundo em que a flexibilização das leis de alguns países trouxe resultados bastante positivos; alguns apresentando regras especiais para certos entes subnacionais, outros adotando-as para todas as unidades de seus territórios. No caso brasileiro, percebe-se o aumento gradual das negociações internacionais que muitas vezes resultam em "acordos" entre estados e municípios com seus congêneres de outros países e até mesmo com organizações internacionais. Ora, tais procedimentos são da competência da União, por intermédio de sua diplomacia formal. Por outro lado, mesmo diante dessa ilegalidade a olhos vistos, poucas são as iniciativas legislativas no sentido de adaptação da norma ao mundo dos fatos.

A essência da questão em debate se insere em uma discussão maior que é o federalismo e as suas contradições a partir da Constituição Federal de 1988. Mas esse não é o escopo deste artigo, que se limita, meramente, a analisar a crescente paradiplomacia no país e suas consequências para a sociedade e para o Estado. 


\section{A PARADIPLOMACIA NO MUNDO}

A dificuldade de aceitação da paradiplomacia não é uma exclusividade do Brasil. Como se verá neste tópico, a questão tem merecido atenção de estudiosos em diversas partes do mundo, ensejando soluções jurídicas diferenciadas para atender a realidades em contextos nacionais muito próprios.

A diplomacia consiste, em linhas gerais, na condução de negociações no plano internacional por representantes dos Estados com a perspectiva de atender aos interesses definidos pelas políticas externas de seus governos, normalmente relacionadas a temas de guerra e paz, economia, tecnologia, meio ambiente, comércio e cultura. Como se sabe, é a ação diplomática desses representantes nacionais especializados - os diplomatas - que engendra a teia de interesses mútuos que pode culminar, segundo rito próprio, com a celebração de tratados que legitimam as vontades estatais e consensuais no campo do Direito Público Internacional, garantindo os atos e responsabilidades decorrentes.

Entretanto, diante da dinâmica da globalização, unidades subnacionais (províncias, estados, departamentos, cantões e até mesmo de níveis inferiores) têm protagonizado iniciativas no plano internacional que contrariam a lógica de poder tradicional consagrada pelo sistema westphaliano. $\mathrm{Na}$ tentativa de solucionar problemas regionais que lhes afetam diretamente, esses atores não tradicionais da cena internacional - que talvez não estejam merecendo a devida atenção dos Estados que integram - têm se lançado na "arte diplomática", buscando alcançar resultados que a rigor são da competência da diplomacia oficial estatal. Assim, certas negociações estão cada vez mais sendo conduzidas por representantes de unidades subnacionais, caracterizando uma atividade que passou a ser denominada pelo neologismo paradiplomacia - ou cooperação internacional descentralizada -, que encontra fundamentos na teoria democrática e em conceitos como mundialização do Direito, autodeterminação dos povos, subsidiariedade, identidade, soberania relativa e outras teorias afins.

Com maior ou menor grau de intensidade, identifica-se uma tendência dos Estados nacionais em descentralizar competências para seus entes subnacionais; estes, por sua vez, veem-se aptos a se relacionarem com seus correspondentes de outros Estados. Vencidos alguns desafios, talvez a paradiplomacia seja um dia absorvida por todos os Estados em seus ordenamentos internos, como instrumento de mundialização do Direito. Para isso, o Direito precisa exercer o seu papel organizativo. "Se é verdade que a mundialização conduz a uma relação progressiva de competência exclusiva dos Estados em prol das competências compartilhadas, o papel do Direito seria o de edificar princípios de organização dos povos para organizar o compartilhamento de competências de modo compatível com a soberania". ${ }^{1}$

Conceitualmente, paradiplomacia se refere a uma emergente capacidade do exercício da política externa por unidades subnacionais; ou seja, refere-se à participação dessas unidades, independente do Estado central, na busca de seus próprios interesses na arena internacional. ${ }^{2}$ Também é apresentada como uma atividade com a função de integração e de cooperação, na qual a racionalização da política externa realizada por uma soma de esforços entre o governo federal e as unidades subnacionais poderia produzir resultados positivos para a diplomacia nacional. Nessa linha de argumentação, propõe-se uma descentralização da política externa, na qual o governo central atuaria como coordenador da ação externa de suas unidades, de forma a garantir uma harmonia entre todos os Estados subnacionais e deles com a política nacional para o plano externo. Essa autonomia de unidades subnacionais contribuiria para o alcance de objetivos mais concretos em termos de política externa, maiores avanços nas negociações e maior satisfação dos interesses regionais. ${ }^{3}$ Alguns auto-

1 DELMAS-MARTY, Mireille. Três desafios para um direito mundial. Tradução e posfácio de Fauzi Hassan Choukr. Rio de Janeiro: Lumen Juris, 2003. p. 171.

2 WOLFF, Stefan. Paradiplomacy: scope, opportunities and challenges. Bologna Center Journal of International Affairs, John Hopkins University (UK), v. 10, 2007. Disponível em: <http://bcjournal.org/volume-10/>. Acesso em: 24 fev. 2012. WOLFF é Ph.D. em Ciência Política na London School of Economics e professor da University of Nottingham (Reino Unido).

3 SOLDATOS, Panayotis; MICHELMANN, Hans. Federalism and international relations: the role of subnational units. Oxford: Clar- 
res registram um tipo particular de paradiplomacia: a protodiplomacia, que seria um ativismo político segundo o qual governos locais buscam apoio internacional para causas independentistas.

O fenômeno encontra razões consistentes para o seu incremento, mesmo diante de fortes resistências dos Estados. Razões de ordem econômica, política e cultural explicam as motivações que conduzem os entes subnacionais a atuarem no plano internacional. ${ }^{4}$ Entre as razões de ordem econômica, assinala-se, principalmente, a cooperação transfronteiriça na promoção de infraestrutura e a resolução de problemas comuns (produção, comércio, educação, saúde, meio ambiente), por julgarem os governos locais que os governos centrais não dedicam suficiente atenção às suas necessidades prementes ou não estão equipados para tanto. Razões de ordem política são as decorrentes de aspirações nacionalistas que buscam alcançar a independência política, ou um meio para obtenção de maior reconhecimento junto à comunidade internacional ou ainda quando identificam um declínio de confiança depositada nos governos centrais nacionais. As razões de ordem cultural são as motivações típicas dos Estados multinacionais com relação às suas diásporas, revestindo-se de intenção política e ou religiosa, quando as minorias étnicas buscam influenciar a mobilização de governos subnacionais para obtenção de apoio e assistência em suas pátrias de origem no trato com os governos dos Estados que as abrigam.

Existem modelos emblemáticos de paradiplomacias institucionalizadas no mundo. ${ }^{5}$ Alguns Estados apresentam regramentos gerais para todos os seus entes subnacionais e outros apresentam regramentos diferenciados. Encontramos, por exemplo, na Alemanha, na Argentina, no Canadá e na Suíça, regramentos gerais uniformes para as suas unidades. $\mathrm{Na}$ Alemanha, constitucionalmente, tem-se como obrigatório para o Estado a consulta a suas unidades - os länder - sempre que a matéria tratada venha a afetar questões de suas competências; os länder podem, inclusive, concluir tratados internacionais. Na nossa vizinha Argentina, com a reforma constitucional de 1994, há a possibilidade de as provinciais celebrarem tratados internacionais, desde que não estejam em desacordo com a política exterior da nação e não afetem as faculdades delegadas ao governo federal ou o crédito público da nação, sendo necessário o conhecimento prévio do Congresso Nacional. No Canadá, os governos provinciais participam ativamente das negociações internacionais, como, por exemplo, no âmbito da NAFTA. Para a assinatura do Protocolo de Kyoto, foi necessário realizar reuniões para a discussão e consentimento entre as províncias canadenses. Muitas delas possuem escritórios de representação no exterior. De acordo com a Constituição da Suíça, a condução das relações externas é de competência federal, porém, o seu exercício deverá levar em consideração a vontade dos cantões.

Entre os Estados que apresentam regramentos diferenciados dentro de um mesmo território, figuram a Bélgica, a Espanha e o Reino Unido. Na Bélgica, o governo de Flandres pode celebrar tratados com terceiras partes, dispor de representações no exterior, participar com delegados em negociações multilaterais e participar formalmente da formulação das políticas externas belgas em suas áreas de interesse. O governo central tem apenas um papel de coordenação. Outro exemplo desse modelo é a Catalunha. Muito embora a Constituição da Espanha explicitamente retenha a competência pelas relações internacionais no governo central, a Catalunha goza de poderes especiais por conta do sistema de devolução de poderes, especialmente nas áreas de economia, educação e turismo. A região celebra acordos com outras entidades e assume o papel de "pátria-mãe" das coetnias fora do território espanhol. O Reino Unido opera um sistema assimétrico de devolução das regiões da Irlanda do Norte, da Escócia e do País de Gales com diferentes níveis de autonomia do governo central em Westminster. A mais autônoma é a Escócia, mesmo assim, sua presença na arena internacional é restrita, podendo promover a imagem positiva no exterior e interesses da região quanto à política de devolução na União Europeia e além

endon Press, 1990. p. 220. SOLDATOS é professor de Ciência Política na Université de Montréal (Canadá) e coeditor do Journal of European Integration (Luxembugo) e a quem se atribui o primeiro uso do termo "paradiplomacia".

4 LESSA, José Vicente da Silva. Paradiplomacia no Brasil e no mundo: o poder de celebrar tratados dos governos não centrais. Viçosa, MG: UFV, 2007. p. 36.

5 Ver LESSA, José Vicente da Silva. Paradiplomacia no Brasil e no mundo: o poder de celebrar tratados dos governos não centrais. Viçosa, MG: UFV, 2007. p. 45-105. O autor apresenta, resumidamente, alguns modelos mais característicos de paradiplomacias no mundo. 
dela; e ainda, celebrar acordos de cooperação dentro da União Europeia com a Bavária, Catalunha e comitês regionais das regiões marítimas.

Nos exemplos apresentados, ainda que colocados de maneira superficial, percebe-se que as constituições recepcionaram o conceito de descentralização de alguns poderes antes exclusivos do ente central, aumentando a autonomia das subunidades no campo das relações internacionais. Para tal, criaram condições e critérios para o funcionamento da atividade paradiplomática, tanto nas próprias cartas magnas quanto na legislação regulamentadora, mas sempre deixando claro que o controle soberano estatal é inegociável.

\section{A paradiplomacia no Brasil}

\subsection{Caracterização}

Reduzido ao essencial para o propósito deste trabalho, a paradiplomacia que se efetiva no Brasil pode ser caracterizada como sendo um fenômeno: (i) inescapável, por conta de irrefreável processo globalizante que o estimula; (ii) fático, uma vez que se manifesta concretamente e em tendência crescente no país; e (iii) desejável, uma vez que traz, em tese, benefícios a comunidades locais e regionais. Essas três características por si só não constituiriam um problema no campo do Direito se a atividade fosse exercida com o devido respaldo no ordenamento jurídico nacional. Mas não é. Não obstante a constatação de se tratar de um fenômeno real e crescente, o procedimento entra em conflito com a Constituição que remete à competência da União o trato de questões internacionais.

Para que se tenha uma ideia geral da dinâmica crescente e aparentemente inevitável da paradiplomacia no país, José Vicente Lessa, na obra já citada, destaca em sua pesquisa a existência de sessenta e cinco ocorrências da atividade em estados e municípios, em 2006, com vizinhos, países europeus e asiáticos e com os Estados Unidos. As relações internacionais mantidas por esses entes subnacionais brasileiros acontecem especialmente na região de fronteira e ou onde o vetor socioeconômico está imerso intensamente nas dinâmicas dos fluxos econômicos globalizantes.

Tendo como quadro referencial aquelas razões que impulsionam a paradiplomacia no mundo - de ordem econômica, política e cultural - é possível afastar as principais causas políticas e culturais e identificar claramente as de ordem econômica no caso brasileiro. O Brasil não é um Estado multinacional e tampouco experimentou diásporas. Também não se configuram minorias étnicas com interesse e capacidade para mobilização de governos estaduais ou municipais com vistas à obtenção de "assistência em suas pátrias de origem". Assim, não se identificam razões de ordem cultural motivadoras da paradiplomacia em território nacional. Também as razões de ordem política - "aspirações nacionalistas" e "busca de reconhecimento junto à comunidade internacional" - não constituem fatores que motivam a paradiplomacia brasileira, apesar da percepção que ocorre algum "declínio de confiança depositada no governo central".

São as razões de ordem econômica que melhor justificam a reprodução da paradiplomacia no Brasil. É perceptível que os entes subnacionais buscam captar investimentos, ampliar mercados, promover negócios entre empresas, transferir ou absorver tecnologias e estimular o turismo. Nas áreas contíguas com os vizinhos sul-americanos, buscam implementar programas mais duradouros de cooperação transfronteiriça, como na promoção de obras de infraestrutura e na resolução de problemas de interesse comum referentes à produção e ao comércio que findam por impactar outros campos, como o da educação e o da saúde.

O problema que se apresenta não são as negociações em si - até desejáveis sob certo ângulo diante dos imperativos contemporâneos que determinam a máxima integração no sistema econômico transnacional. O problema é o fato de ocorrerem em manifesto descumprimento da norma constitucional, como pode ser depreendido dos dispositivos enunciados a seguir: 
(a) do art. 21 - compete à União "manter relações com Estados estrangeiros e participar de organizações internacionais" (inciso I).

(b) do art. 49 - é da competência exclusiva do Congresso Nacional "resolver definitivamente sobre tratados, acordos ou atos internacionais que acarretem encargos gravosos ao patrimônio nacional" (inciso I).

(c) do art. 52 - dispõe que compete privativamente ao Senado Federal "autorizar as operações externas de natureza financeira, de interesse da União, dos Estados, do Distrito Federal, dos Territórios e dos Municípios" (inciso V).

(d) do art. 84 - dispõe que compete privativamente ao Presidente da República "celebrar tratados, convenções e atos internacionais, sujeitos a referendo do Congresso Nacional” (inciso VIII).

A rigor, portanto, não há espaço no Direito Público Interno para o exercício legal da paradiplomacia, uma vez que "manter relações com Estados estrangeiros" compete à União, sem extensão dessa competência aos membros da federação. Quando essa atividade informal abrange a celebração de acordos, mais grave se torna a irregularidade, uma vez que é da competência privativa do Presidente da República "celebrar tratados" e que mesmo esses estão sujeitos a rito próprio no Congresso Nacional.

No fluxo de uma tendência global de descentralização de poderes centrais, o Estado brasileiro se mostra confuso e incapaz de se ajustar à realidade dos fatos, tornando-se refém de sua própria legislação e da ação pouco perceptível de forças de sua estrutura que se digladiam nos bastidores da política, inspiradas em princípios universais, muitas vezes descolados do interesse nacional.

\subsection{A postura resistente do estado}

Quando se pensa em relações internacionais conduzidas por entes subnacionais, a primeira reação é de possível perda de soberania, por sugerir a concessão de determinado grau de autonomia. A doutrina clássica do Direito, quando interpreta as soberanias nacionais, vincula o conceito de soberania à capacidade do Estado, entre outros atributos, em conduzir sua política externa e manter relações diplomáticas com Estados estrangeiros. Nessa linha doutrinária tradicional, teme-se que, ao permitir que os entes subnacionais conduzam suas próprias relações internacionais, a soberania do governo central possa ser ameaçada pela existência de projetos que não coincidam com os do Estado. Acredita-se que "[...] o crescente envolvimento internacional das entidades subnacionais tem sido um movimento que os governos nacionais tendem a ver negativamente, ou ao menos a manter dentro de estreitos limites. A concepção realista, estatocêntrica, sugere que a coerência e a unidade da política exterior sejam necessárias para evitar qualquer vantagem para adversários ou mesmo para parceiros."

E assim, sob argumento político baseado no princípio da soberania, o poder central do Estado brasileiro reluta em ceder parte de sua prerrogativa de "manter relações com Estados estrangeiros". O entendimento é que essa relutância ocorre porque existe uma cultura institucional, de viés conservador, que determina procedimentos que se orientam em sentido oposto à tendência mundial, contrariando os anseios dos estados e municípios. Nesse viés, o princípio da subsidiariedade do direito comunitário europeu, quando invocado, é de imediato afastado, argumentando-se que não dará respostas precisas aos problemas nacionais.

Estudos realizados no Brasil indicam que os órgãos do poder central apresentam diferentes percepções quanto à questão da descentralização das ações da União nessa matéria, manifestando-se como "forças" que atuam em sentidos opostos - uma "força centrípeta" e uma "força centrífuga" - na relação entre o governo central e os poderes locais.? A "força centrípeta” representaria o pensamento e ações dos órgãos do governo

6 VIGEVANI, Tullo. Problemas para a atividade internacional das unidades subnacionais: estados e municípios brasileiros. Revista Brasileira de Ciências Sociais, São Paulo, v. 21, n. 62, p. 128, 2006.

7 CACHAPUZ DE MEDEIROS, Antonio Paulo. Introdução. In: LESSA, José Vicente da Silva. Paradiplomacia no Brasil e no 
central que até permitem ações autônomas das unidades subnacionais desde que as regule e as controle; já a "força centrífuga", como se verá mais adiante e como o termo sugere, operaria no sentido da descentralização com o mínimo de controle.

$\mathrm{Na}$ corrente resistente, conservadora, percebe-se que ainda permeia no inconsciente dos tomadores de decisão incrustados na administração dos três Poderes o apego ao subjetivismo da soberania. Grande parte dos políticos, diplomatas, militares, aplicadores e intérpretes do Direito no plano federal reagem a qualquer ideia que possa sugerir perda de soberania, alinhados que são com a perspectiva realista na qual o Estado central continua sendo o único ator legítimo para lidar com as tratativas no campo internacional. São esses agentes que participam dos processos decisórios de órgãos federais e atuam como "força centrípeta", constituindo-se em fator que dificulta ou mesmo impede o desenvolvimento da atividade paradiplomática no rumo da institucionalização.

Esse proceder resistente do poder central talvez ocorra em face da ausência de instituições suficientemente maduras para lidar com esse fenômeno historicamente recente no campo das relações internacionais, que é observado nos três níveis da administração pública brasileira. Se a avaliação é correta, é de se supor que em horizonte não muito distante as instituições amadureçam e consigam desatar o nó em que o país se encontra.

A Constituição Federal de 1988 fortaleceu o princípio do federalismo a ponto de inserir em seu corpo uma cláusula pétrea que impede apresentação de emendas que intentem abolir a forma federativa de Estado ( $\left(4^{\circ}\right.$, artigo 60 ), além de outros dispositivos que trazem a leitura de uma diminuição da centralização do poder da União observada nas Cartas anteriores. Entretanto, o que se constata nas últimas décadas é a manutenção de rígido controle da União em várias matérias que a legislação foi conformando para atender a demandas políticas, seja cerceando a autonomia das unidades, seja impedindo que se promova uma progressiva liberalização.

\subsection{A postura tolerante do Estado}

Embora a Constituição Federal apresente limites à atuação internacional de seus entes federados, a paradiplomacia é na prática "tolerada" no Brasil. Diante da escassez de recursos e da diversidade de interesses da população, o Estado de hoje enfrenta sérias dificuldades para alcançar o bem-estar social, sobretudo em razão de sua estrutura de poder centralizada, burocratizada e hierarquizada. Essa circunstância gera espaço para a atuação de outros entes mais identificados com as necessidades locais e regionais. Nesse contexto, ganha espaço no Brasil a visão da paradiplomacia sob a ótica do princípio da subsidiariedade aplicado no direito comunitário europeu.

O princípio da subsidiariedade encontra-se destacado no artigo $5^{\circ}$ do Tratado da Comunidade Europeia, consolidado no ordenamento jurídico comunitário no contexto do processo de integração, a partir do Tratado de Maastricht. Existe como filosofia desde a Grécia antiga e se firmou historicamente na Doutrina Social da Igreja Católica. A União Europeia definiu uma abordagem global para a aplicação do princípio da subsidiariedade, prevendo princípios fundamentais, diretrizes e procedimentos com a finalidade de prestigiar as comunidades regionais. Tal princípio é rotineiramente enfatizado nas principais decisões políticas nas quais é destacado o caráter de obrigatoriedade de sua observância. ${ }^{8}$

A nossa própria Constituição Federal abre perspectivas nesse campo ao ampliar as atribuições de estados e municípios - com o pacto federativo - que fortalecem a discussão sobre a possibilidade de permitir-lhes

mundo: o poder de celebrar tratados dos governos não centrais. Viçosa, MG: UFV, 2007. p. 29-38.

8 O Parecer do Comitê das Regiões da União Europeia (2011), no item "B. Subsidiariedade", "Recorda que o Tratado de Lisboa faz uma referência explícita à autonomia local e regional e à dimensão local e regional do princípio da subsidiariedade, o que significa que a UE tem de respeitar as competências dos órgãos de poder local e regional quando propõe e adopta nova legislação baseada em competências partilhadas.". Parecer do Comité das Regiões sobre regulamentação inteligente, de 11/10/2011, publicado no Jornal Oficial (da União Europeia) no C 009, de 11/01/2012, p. 0014 - 0017. Disponível em: <http://eur-lex.europa.eu/LexUriServ/ LexUriServ.do?uri=OJ:C:2012:009:0014:01:PT:HTML>. Acesso em: 28 fev. 2012. 
efetividade no trato de ações internacionais descentralizadas. Como consequências concretas dessa flexibilização, em 2003, foi criado a Assessoria de Cooperação Internacional Federativa do Ministério das Relações Exteriores, bem como, em 2004, a Subchefia de Assuntos Federativos da Presidência da República. São indicativos de uma maior atenção da União com as questões federativas e internacionais quando comparados com os períodos históricos precedentes. No entanto, “[...] a orientação geral desse processo não é clara e também não há homogeneidade no governo no sentido de procurar elevar a capacidade nacional de promoção da inserção internacional dos governos subnacionais". "

Dentro da perspectiva de que existem "forças" na relação entre o governo central e os poderes locais que operam em sentidos opostos, os órgãos que se manifestam como "força centrífuga" apresentam um caráter inovador, não atribuindo ao subjetivismo da soberania um valor além daquele visualizado no plano prático. Inspirados no princípio da subsidiariedade - ou não - os tomadores de decisão que constituem essa força centrífuga acham-se compelidos a compreender melhor as demandas das unidades subnacionais. Nos órgãos do poder central, as iniciativas no rumo da institucionalização são tênues quando comparadas ao poder das forças centrípetas; mas ocorrem, e em tendência crescente. Assim, diante da percepção, por um lado, da inexorabilidade do fenômeno, e por outro, da inspiração no princípio da subsidiariedade por parte dos órgãos e agentes da estrutura do poder central, identifica-se hoje um Estado tolerante quanto ao crescimento a olhos vistos de um modelo de paradiplomacia que opera na informalidade jurídica.

\subsection{Consequências da dupla postura do Estado}

Resumidamente, tem-se que o Estado brasileiro mostra-se resistente quanto à flexibilização da paradiplomacia por temer perder parte da autoridade soberana sobre seus membros. Para isso, invoca o princípio clássico da soberania em ações e omissões que se manifestam a partir dos tomadores de decisão que mobíliam os órgãos do poder central, dificultando o desenvolvimento da paradiplomacia. Ao mesmo tempo, o Estado é tolerante, na medida em que percebe a paradiplomacia como fenômeno inescapável, manifestando essa tolerância em ações conduzidas por alguns tomadores de decisão dos órgãos federais que relativizam o princípio da soberania, inspirados no princípio da subsidiariedade. Ocorre, pois, uma dupla circunstância em que o Estado é ao mesmo tempo resistente e tolerante com o exercício não institucionalizado da paradiplomacia.

Da postura resistente, decorre o sentido de negação das iniciativas no rumo da institucionalização. Da postura tolerante, tem-se a não coibição da ilegalidade, implicando uma quase "autorização" à continuidade da dinâmica instaurada. Diante desse desenho, e não se visualizando em horizonte perceptível a alteração concreta desse status quo, podem ser apontadas quatro consequências ao Estado brasileiro que se acham inter-relacionadas: (i) prejuízos ao desenvolvimento local e regional; (ii) insegurança jurídica; (iii) constrangimentos no plano internacional; e (iv) riscos à segurança nacional.

A primeira consequência - os prejuízos socioeconômicos - é decorrente do caráter restritivo da norma, que inibe uma maior participação nas transações econômicas e nas iniciativas conjuntas no campo social, freando os interesses de estados e municípios que aspiram incrementar seus intercâmbios visando à melhoria das condições de vida locais.

A questão da insegurança jurídica gerada dispensa maiores comentários. É de se supor que as tratativas que ocorrem no cotidiano dos entes subnacionais contenham um fator de risco jurídico intrínseco, tanto para os entes subnacionais quanto para os estrangeiros congêneres que, cientes da ocorrência de certas transações, a rigor, ao arrepio da lei, sustentam-se no ideário racionalista pacta sunt servanda e apostam na não necessidade de apelo a tribunais caso o acordado não se conforme com os fatos.

9 CENTRO DE ESTUDOS DE CULTURA CONTEMPORÂNEA (PUC-SP). Gestão Pública e Inserção Internacional das Cidades. $1^{\circ}$ Relatório Científico (Processo FAPESP nº 03/12953-0). São Paulo: CEDEC, 2006. Disponível em: <http://www.labmundo.org/ disciplinas/VIGEVANI_paradiplomacia_primeiro_segundo_relatorio_cientificos.pdf>. Acesso em: 29 fev. 2012. 
As terceira e quarta consequências - os constrangimentos internacionais ao Estado e riscos à segurança nacional - constituem o foco deste artigo e são apresentadas como uma nova perspectiva de enxergar a questão quando comparada à abordagem de outros autores, no tópico que se segue.

\section{Constrangimentos internacionais e riscos à Segurança nacional}

\subsection{A falta de critérios e condições de funcionamento da atividade paradiplomática}

Apesar de o pacto federativo sugerir alguma descentralização do poder central, a Constituição Federal não sinalizou e nem se previu regulação amiúde para o trato das possíveis ações descentralizadas de entes subnacionais no campo internacional. O Governo Federal apenas monitora empiricamente a paradiplomacia nacional; mas é um monitoramento frágil, incapaz de proporcionar ao Estado um termômetro que indique o real nível de cooperação internacional e suas implicações para a política exterior. Justamente por quase não existirem critérios e condições, várias ações se efetivam a revelia do olhar do Estado e podem comprometer os interesses nacionais e até mesmo dos próprios interessados. Diante da falta de critérios jurídicos claros e bem definidos, a atuação descentralizada no âmbito internacional guarda um potencial de risco para o Estado ou, no mínimo, submete-o a constrangimentos.

A ausência de um monitoramento formal por parte dos órgãos federais não permite a adequada avaliação da cooperação internacional descentralizada, dificultando a distinção entre experiências bem e mal sucedidas. Em não havendo uma definição clara de objetivos e nem indicadores de mensuração para avaliar se determinado projeto está, de fato, trazendo benefícios ao ente e ao país ou não, a cooperação descentralizada pode passar ao largo do interesse nacional.

Como o Estado brasileiro se mantém com a dupla postura diante da paradiplomacia, determinando uma situação de continuidade sem institucionalidade, não é factível a criação de suficientes mecanismos legais que permitam ao Governo Federal o adequado monitoramento e avaliação da ação internacional em seus diferentes graus de descentralização. Essa situação constitui o principal fator que propicia a existência de riscos e constrangimentos. O problema deixa de ser apenas no campo jurídico e passa a ser político - da high politics, no dizer dos realistas - uma vez que envolve a própria questão da soberania do Estado.

\subsection{0 potencial de conflito com a política externa nacional}

Adotemos como definição simplificada de política externa o conjunto de objetivos políticos que um determinado Estado almeja alcançar nas suas relações com os demais países do mundo, concebida com a finalidade de proteger os interesses nacionais de um país com vistas à segurança nacional, à prosperidade socioeconômica e à preservação de valores nacionais.

Os governos locais cada vez mais se lançam em iniciativas no campo internacional que visam ao incremento do desenvolvimento socioeconômico de seus estados e municípios. Enxergam oportunidades para a solução de problemas a partir da cooperação com congêneres no além-fronteira, advindo resultados práticos de maneira muito mais eficaz que aqueles proporcionados pelo poder central. Esses governos não estão necessariamente preocupados com os difusos “interesses nacionais” e as suas políticas públicas, especialmente daquelas regiões mais afastadas geograficamente do poder central, não são necessariamente harmônicas e ou convergentes com a política externa do governo central, estabelecendo-se assim uma relação que pode ser conflituosa. 
Assinala-se na ação paradiplomática dos entes subnacionais um potencial de conflito com a política externa do Estado que os integra. Tal potencial é um tema recorrente, tanto na literatura como na práxis, apesar da pouca probabilidade que conflitos se manifestem no Brasil.

A literatura indica que, apesar dos riscos, isso dificilmente acontece, a não ser quando há crises abertas do sistema federativo, como ocorreu no Canadá nos anos de 1960, ou quando há intenções secessionistas por algum motivo - étnico, linguístico, nacional ou outro -, como sucedeu na ex-Iugoslávia na década de 1990. De todo modo, esse conflito potencial - ou suas formas de resolução - entre governos locais e governo central é um ponto central quando se discute a política externa dos entes subnacionais. ${ }^{10}$

A ação dos entes subnacionais no Brasil depende muito mais da correlação entre forças políticas, capazes de tolher ou incentivar iniciativas no plano internacional, do que de uma orientação racional conduzida pelo Estado (leia-se "Itamaraty"). Como se sabe, essas forças com interesses políticos locais não são necessariamente alinhadas com os interesses da federação, o que supõe um risco inerente de conflito com a política exterior capaz de deixar o Estado sob constrangimento, na medida em que não consegue explicar o alinhamento dos interesses locais com os nacionais perante a comunidade internacional.

\subsection{A fragilização de certos elementos de controle da segurança nacional}

A paradiplomacia conduzida à revelia da União pode conter elementos que ensejam ameaças potenciais no campo da segurança nacional. Não é de se supor que preocupações mais elevadas com a segurança do Estado nacional sejam levadas em conta durante as negociações locais e regionais, até mesmo porque ameaças dessa natureza são de difícil percepção. Quando muito, os governos locais tratam da defesa nacional como sinônimo de segurança pública, em matérias relacionadas ao combate a crimes e ilícitos transnacionais, de natureza meramente policial.

Assim, tratativas que resultam, por exemplo, em abertura de uma estrada ou construção de uma ponte interligando dois países, que por um lado corresponde a uma demanda de integração socioeconômica regional, pode por outro viés estar ensejando a criação de uma "penetrante" - para usar a terminologia militar - que terá importantes repercussões nos planejamentos estratégicos da defesa nacional. A partir daquele fato consumado, por exemplo, a via de acesso aberta pode eventualmente dificultar a defesa territorial, ao possibilitar o acesso de meios militares estrangeiros, a partir de bases localizadas em cidades a milhares de quilômetros da fronteira - uma preocupação, portanto, absolutamente imperceptível aos olhos dos paradiplomatas locais. Quando uma tratativa como essa é conduzida pela diplomacia estatal, por certo o Conselho de Defesa Nacional (Lei 6.634/79) é ouvido pelo Itamaraty e opina quanto às implicações para a segurança nacional, sugerindo, por exemplo, uma estrutura de ponte mais ou menos larga - para possibilitar/inviabilizar a passagem de uma coluna de blindados de certa categoria, conforme avaliação estratégica militar. Ou, ainda, poderia apresentar parâmetros a serem seguidos quanto ao vão da ponte como determinante técnica de passagem de certas classes de embarcações.

Não é improvável o desenho de um cenário que contemple, por exemplo, imensas terras indígenas na faixa de fronteira da Amazônia em que populações locais sejam manipuladas com relativa facilidade por organizações não governamentais não alinhadas com os interesses nacionais. ${ }^{11}$ Essas organizações, em boa medida de caráter internacional, costumam manter regulares "negociações" com organizações similares do outro lado da fronteira, não raro, recorrendo a princípios como o de autodeterminação dos povos, e podem vir a trazer embaraços políticos ao Estado se não forem adequadamente monitoradas. ${ }^{12}$

10 VIGEVANI, Tullo. Problemas para a atividade internacional das unidades subnacionais: estados e municípios brasileiros. Revista Brasileira de Ciências Sociais, São Paulo, v. 21, n. 62, p.130, periodicidade, 2006.

11 Não há indicativos que apontem para a conformação dessa situação, mas a hipótese não pode ser descurada. O autor é assessor de política e estratégia do Ministério da Defesa e participa da elaboração de cenários de segurança que contemplam o espaço definido pela faixa de fronteira na Amazônia.

12 A Política de Defesa Nacional (PDN), no capítulo "4. BRASIL", destaca que "A Amazônia brasileira, com seu grande poten- 
Nessa linha de argumentação, existe ainda a hipótese, que não pode deixar de ser considerada, de que outros Estados estimulem posicionamentos contrários ao governo central, ensejando, em caso extremo, um quadro de guerra civil. Nestes dois casos, a paradiplomacia promovida é qualificada como protodiplomacia.

Presentemente, existe uma tentativa de diminuição de um importante mecanismo de controle da faixa de fronteira. A Confederação Nacional de Municípios tem se manifestado nos fóruns em que organiza ou participa com postura que promove campanha para a redução ou mesmo extinção da faixa de fronteira de 150 quilômetros. ${ }^{13}$ Esse instrumento jurídico que tem origem no período imperial está resguardado pela Constituição Federal em seu artigo 20 e regulamentado pela Lei 6.634/79. O dispositivo remete ao Conselho de Defesa Nacional o crivo de assentimento prévio para autorizar certas atividades consideradas estratégicas, entre elas o estabelecimento de indústrias sensíveis e atividades econômicas estrangeiras. Essa campanha tem encontrado eco em parlamentares que regularmente apresentam propostas legislativas no sentido de alterar aquele dispositivo legal. Não deixa de ser um reflexo da paradiplomacia não institucionalizada que não consegue calibrar o interesse dos entes subnacionais levando em conta o interesse nacional.

\subsection{A fragilização de certos elementos de controle de políticas socioeconômicas}

Uma associação de estados subnacionais fronteiriços de países vizinhos ${ }^{14}$ que, mediante "acordo internacional" regional, delibere sobre facilidade de trânsito de seus nacionais sem maiores restrições, com vistas a proporcionar maior liberdade no ir e vir das populações, pode ensejar um indesejável fluxo migratório, além de facilitar o ingresso de criminosos transnacionais, ou mesmo causar um problema diplomático se provocar uma dinâmica populacional imprevista, determinando a transposição de grandes aglomerados pelas fronteiras.

Essas mesmas unidades subnacionais, ao "acordar", por exemplo, sobre ingênuas trocas comerciais de produtos agrícolas ou mesmo de animais, sob o rótulo de economia de "subsistência", podem estar satisfazendo interesses imediatos dos fronteiriços, mas possa também, sem se darem conta, possibilitar e até estimular o ingresso de pragas e zoonoses, cujos órgãos reguladores não participaram das negociações. A possibilidade de o Amapá se constituir em porta de entrada da praga agrícola "mosca da carambola", oriunda da Guiana Francesa, é uma ilustração desse risco, caso a cooperação transfronteiriça ocorra sem instrumento de controle do Ministério da Agricultura Pecuária e Abastecimento. ${ }^{15}$

No campo das operações externas de natureza financeira, não obstante as limitações impostas pela Constituição Federal, que exige a autorização pelo Senado (art. 52, inciso V), ainda assim, há risco de eventual endividamento ultrapassar a barreira da autonomia. Diante da percepção acerca da lentidão do processo de autorização pelo Senado, e até mesmo das ingerências políticas, entes subnacionais poderiam se obrigar externamente em extensão maior do que internamente podem fazê-lo, sem o aval do poder central. Como desfazer tal constrangimento se a União não atuou como garantidora do endividamento?

cial de riquezas naturais e de biodiversidade, é foco da atenção internacional. [...]. Estas características facilitam a prática de ilícitos transacionais e crimes conexos, além de possibilitar a presença de grupos com objetivos contrários aos interesses nacionais". 2005, p. 10 .

13 "Ainda que não esteja explicitamente caracterizada nos dispositivos legais, a filosofia do modelo brasileiro de faixa de fronteira contempla, por um lado, a preocupação com a segurança nacional e, por outro, a intenção de levar o desenvolvimento às regiões mais afastadas dos centros do poder. Segurança e desenvolvimento constituem um binômio cuja dinâmica se estabelece, idealmente, por via da integração das regiões abrangidas ao núcleo central do país". ABREU, Gustavo de Souza. Modelo brasileiro de faixa de fronteira: um imperativo estratégico a ser mantido ou uma concepção ultrapassada? Revista A Defesa Nacional, Rio de Janeiro, n. 815, p. 33, 2009.

14 Um exemplo de associação dessa natureza é a "Iniciativa MAP" - Associação dos Estados/Províncias de Madre de Dios (Bolívia), Acre (Brasil) e Pando (Peru).

15 No âmbito das negociações Brasil-França, por conta do Acordo-Quadro entre esses países (Decreto 2.200/97), ao lado das tratativas de cooperação transfronteiriça oficiais conduzidas pelo Itamaraty, e com participação de diversos ministérios, ocorrem "negociações" paralelas em todos os níveis, tendo como atores o Estado do Amapá, o Município de Oiapoque, empresas privadas e organizações não governamentais, interagindo com os correspondentes da parte francesa. 
As hipóteses e exemplos apresentados têm por base situações concretas extraídas da realidade nacional. Algumas delas são portadoras de graus de risco ao Estado; outras podem causar consideráveis prejuízos econômicos, sociais, ambientais e à saúde humana e animal. O certo é que, no mínimo, podem causar embaraços à diplomacia oficial, além de forçar o Governo Federal a tomar providências internas que, por certo, desagradarão às populações das regiões envolvidas.

\subsection{A ingerência estrangeira em assuntos internos}

A ação de governos nacionais e agências internacionais que utilizam a cooperação como forma de ingerência política, econômica e cultural no campo doméstico de outro Estado é uma prática internacional pouco revelada, mas muito comum, já que esse tipo de atividade normalmente foge ao controle dos governos centrais, principalmente daqueles que não aceitam em seu ordenamento jurídico a paradiplomacia.

Há também a ingerência de organizações não governamentais e empresas privadas que oferecem uma cooperação técnica ou financeira a estados e municípios, via terceiro setor, em troca da exploração de recursos naturais, por exemplo. A facilidade é obtida pela permeabilidade que o campo da paradiplomacia não institucionalizada oferece. Uma ilustração dessa ingerência são as atividades internacionais na Amazônia em que a biodiversidade brasileira é não raro pirateada, contando inclusive com o consentimento de nacionais.

Politicamente, tem-se uma ingerência estrangeira no poder soberano do Estado brasileiro.

\section{Considerações finais}

Não há modelo único ou ideal de paradiplomacia no mundo; os países que adotam tal procedimento possuem regras muito específicas, levados em conta os aspectos econômicos, políticos e culturais, dentro de contextos históricos muito próprios.

A realidade brasileira é muito peculiar. Não temos movimentos rumo à secessão, mas temos uma extensa fronteira de quase $17.000 \mathrm{~km}$, com dez países, com interação socioeconômico local e regional em variados graus em ritmo crescente. Temos estados como São Paulo, com um PIB que se assemelha ao de países europeus, portanto com uma agenda de tratativas internacionais muito intensas, convivendo em um mesmo espaço territorial nacional que o Amapá, cujas demandas culturais recebem tintas indígenas e francesas e busca incessantemente uma porta para a Europa a partir da integração fronteiriça. Enfim, amostras nacionais que bem exemplificam a natureza diversa dos interesses de entes subnacionais no espaço internacional, determinando a ocorrência de "diplomacias" suis generis conduzidas por governos estaduais e municipais que buscam uma forma diferente de incrementar suas políticas públicas de desenvolvimento social e econômico.

O fenômeno da paradiplomacia no Brasil é caracterizado como inescapável, de tendência crescente e desejável por parte das comunidades locais e regionais. Contudo, também se caracteriza pela não institucionalidade, uma vez que se processa em descumprimento ao texto constitucional ao não observar certas competências do poder central no trato de questões internacionais.

Um dos aspectos conclusivos é que o Estado brasileiro apresenta uma dupla postura quanto à paradiplomacia: resiste à institucionalização, mas tolera a prática. Com essa postura, da qual não se evidenciam mudanças em horizonte visível, identificam-se quatro importantes consequências: prejuízos socioeconômicos a entes subnacionais, insegurança jurídica, constrangimentos ao Estado e riscos a certos aspectos da segurança nacional. Estas duas últimas, em particular, decorrem da não vigência de suficientes e adequados critérios e condições legais de funcionamento da atividade, uma vez que a Constituição nem sequer considera o seu exercício formal como competência dos membros federados, não deixando abertura para que a legislação ordinária regule a atividade e estabilize os eventuais conflitos no jogo entre demandas regionais e locais e os interesses federativos. 
Apresenta-se como solução ao problema a tomada de iniciativas, além do discurso, visando ao estabelecimento de um modelo jurídico-institucional adequado ao exercício da atividade paradiplomática pelos estados e municípios, dentro de certos limites, seja por aperfeiçoamento do texto constitucional, seja pelo reconhecimento e legitimação das atuações dos governos subnacionais em legislação infraconstitucional, com a definição clara de critérios e condições de funcionamento, no rumo da institucionalização. O Estado deve dizer claramente o "quanto" de sua soberania pode ser dividido, cedido, delegado. A permanecer pouco inclinado a mudanças, invocando o princípio da soberania, mas ao mesmo tolerante, submete-se a riscos e constrangimentos que, no extremo, poderiam levá-lo, paradoxalmente, até mesmo à perda da autoridade soberana.

Com a institucionalização, a União e os membros federados poderão exercer seus poderes de modo menos conflituoso, com ganhos socioeconômicos para as comunidades que em grande parte dependem do resultado das negociações diretas com seus congêneres internacionais, além de não deixar em xeque a credibilidade brasileira por conta de acordos não reconhecidos pelo Direito Internacional Público e não arriscar a soberania do País, por conta de uma remota, extrema, mas não descartável hipótese de tentativa de emancipação de um ente subnacional, como registra a História em outros contextos.

\section{REFERÊNCIAS}

ABREU, Gustavo de Souza. Modelo brasileiro de faixa de fronteira: um imperativo estratégico a ser mantido ou uma concepção ultrapassada? Revista A Defesa Nacional, Rio de Janeiro, n. 815, p. 33, 2009.

BRASIL. Politica de Defesa Nacional (PDN). Brasília, 2005.

CENTRO DE ESTUDOS DE CULTURA CONTEMPORÂNEA (PUC-SP). Gestão Pública e Inserção Internacional das Cidades. $1^{\circ}$ Relatório Científico (Processo FAPESP nº 03/12953-0). São Paulo: CEDEC, 2006. Disponível em: <http://www.labmundo.org/disciplinas/VIGEVANI_paradiplomacia_primeiro_segundo_relatorio_cientificos.pdf >. Acesso em: 29 fev. 2012.

DELMAS-MARTY, Mireille. Três desafios para um direito mundial. Tradução e posfácio de Fauzi Hassan Choukr. Rio de Janeiro: Lumen Juris, 2003.

LESSA, José Vicente da Silva. Paradiplomacia no Brasil e no mundo: o poder de celebrar tratados dos governos não centrais. Viçosa, MG: UFV, 2007.

SOLDATOS, Panayotis; MICHELMANN, Hans. Federalism and international relations: the role of subnational units. Oxford: Clarendon Press, 1990.

UNIÃO EUROPEIA. Relatório Anual sobre a Subsidiariedade 2010. Ponto 5 da 128. In: REUNIÃO DA MESA DO COMITÊ DAS REGIÕES, p 2-3. Bruxelas, 4 de março de 2011. Disponível em: <http://extranet. cor.europa.eu/subsidiarity/Documents/ Subsidiarity annual report 2010/Subsidiarity Annual Report 2010_ cdr57_11_pt.pdf>. Acesso em: 06 mar. 2012.

VIGEVANI, Tullo. Problemas para a atividade internacional das unidades subnacionais: estados e municípios brasileiros. Revista Brasileira de Ciências Sociais, São Paulo, v. 21, n. 62, 2006.

WOLFF, Stefan. Paradiplomacy: scope, opportunities and challenges. Bologna Center Journal of International Affairs, John Hopkins University (UK), v. 10, 2007. Disponível em: < http:/ /bcjournal.org/volume-10/>. Acesso em: 24 fev. 2012. 
Para publicar na revista Brasileira de Políticas Públicas, acesse o endereço eletrônico www.rbpp.uniceub.br

Observe as normas de publicação, para facilitar e agilizar o trabalho de edição. 